\title{
Prognostic value of renal fractional flow reserve in blood pressure response after renal artery stenting (PREFER study)
}

Jacek Kądziela ${ }^{1}$, Andrzej Januszewicz ${ }^{1}$, Aleksander Prejbisz ${ }^{1}$, Ilona Michałowska ${ }^{1}$ Magdalena Januszewicz ${ }^{2}$, Elżbieta Florczak ${ }^{1}$, Łukasz Kalińczuk ${ }^{1}$, Bożena Norwa-Otto ${ }^{1}$, Ewa Warchoł ${ }^{2}$, Adam Witkowski ${ }^{1}$

${ }^{1}$ Institute of Cardiology, Warsaw, Poland

${ }^{2}$ University of Medicine, Warsaw, Poland

\begin{abstract}
Background: The aim of our study was to determine a potential relationship between resting translesional pressures ratio ( $\mathrm{Pd} / \mathrm{Pa}$ ratio), renal fractional flow reserve $(r F F R)$ and blood pressure response after renal artery stenting.

Methods: Thirty five hypertensive patients (49\% males, mean age 64 years) with at least $60 \%$ stenosis in angiography, underwent renal artery stenting. Translesional systolic pressure gradient (TSPG), Pd/Pa ratio (the ratio of mean distal to lesion and mean proximal pressures) and hyperemic rFFR - after intrarenal administration of papaverine - were measured before stent implantation. Ambulatory blood pressure measurements (ABPM) were recorded before the procedure and after 6 months. The ABPM results were presented as blood pressure changes in subgroups of patients with normal $(\geq 0.9)$ vs. abnormal $(<0.9) \mathrm{Pd} / \mathrm{Pa}$ ratio and normal $(\geq 0.8)$ vs. abnormal $(<0.8)$ rFFR.

Results: Median $P d / P$ a ratio was 0.84 (interquartile range 0.79-0.91) and strongly correlated with TSPG $(r=-0.89, p<0.001)$, minimal lumen diameter $(M L D ; r=0.53, p<0.005)$ and diameter stenosis $(D S ; r=-0.51, p<0.005)$. Median $r F F R$ was 0.78(0.72-0.82). Similarly, significant correlation between $r F F R$ and TSPG $(r=-0.86, p<0.0001)$, as well as with $\operatorname{MLD}(r=0.50, p<0.005)$ and $D S(r=-0.51, p<0.005)$ was observed. Procedural success was obtained in all patients. Baseline Pd/Pa ratio and $r F F R$ did not predict hypertension response after renal artery stenting. Median changes of 24-h systolic/diastolic blood pressure were comparable in patients with abnormal vs. normal $\mathrm{Pd} / \mathrm{Pa}$ ratio $(-4 /-3$ vs. 0/2 $\mathrm{mm} \mathrm{Hg;} p=N S$ ) and with abnormal vs. normal rFFR (-2/-1 vs. $-2 /-0.5 \mathrm{~mm} \mathrm{Hg}$, respectively).

Conclusions: Physiological assessment of renal artery stenosis using $P d / P a$ ratio and papaverine-induced renal fractional flow reserve did not predict hypertension response after renal artery stenting. (Cardiol J 2013; 20, 4: 418-422)
\end{abstract}

Key words: fractional flow reserve, renal artery stenting, pressures ratio

Address for correspondence: Jacek Kądziela, MD, PhD, Institute of Cardiology, ul. Alpejska 42, 04-628 Warszawa, Poland, tel: +48 2234342 72, fax: +48 2261338 19, e-mail: kadziela@ikard.pl 


\section{Introduction}

Atherosclerotic renal artery stenosis (RAS) is one of the common reasons for secondary hypertension [1-3] and increased risk of cardiovascular mortality $[4,5]$. Despite excellent outcomes of renal artery stenting, clinical benefit from revascularization remains controversial [6]. Large randomized controlled trials comparing percutaneous angioplasty and optimal medical therapy did not prove revascularization advantages [7-12]. Thus, the identification of potential predictors for better long-term prognosis after renal stenting may improve appropriate selection of subjects for invasive treatment. During previous years several studies focused on physiological assessment of RAS with intrarenal pressure measurements. Both resting pressures ratio, called " $\mathrm{Pd} / \mathrm{Pa}$ ratio", and hyperemic renal fractional flow reserve ( $\mathrm{rFFR}$ ), after papaverine or dopamine administration became helpful diagnostic tools [13-16]. First studies suggested also that translesional systolic pressure gradient and rFFR may predict the outcome after renal revascularization. The aim of our study was to determine a potential relationship between $\mathrm{Pd} / \mathrm{Pa}$ ratio, rFFR and blood pressure (BP) response after renal artery stenting.

\section{Methods}

\section{Study group}

Out of 44 consecutive hypertensive patients with at least moderate unilateral RAS in noninvasive studies referred to renal angiography, 35 of them (49\% males, mean age 64 years) with at least $60 \%$ stenosis in angiography, underwent renal artery stenting. Clinical examination was performed to determine demographics, duration of hypertension, cardiovascular risk factors, features of vascular disease and related comorbidities. Hypertension was diagnosed according to the World Health Organization (WHO) criteria (BP > 140/90 mm Hg or current antihypertensive treatment with at least 2 drugs). The number of antihypertensive drugs and drug daily doses according to WHO criteria [17] were recorded at baseline and at follow-up visit. Blood samples for all biochemical evaluations were taken after overnight fasting and after 60 min rest in supine position. Baseline serum creatinine was measured before the procedure, estimated glomerular fitration rate (GFR) was calculated using the MDRD formula [18]. Patients with severe valvular disease, NYHA III-IV heart failure and GFR below $30 \mathrm{~mL} / \mathrm{min}$, history of con- trast nephropathy or refusal to provide informed consent were not included.

The study was approved by the Ethics Committee and signed inform consent was obtained from every patient.

\section{Renal angiography}

Renal angiography was performed using standard technique via femoral approach. Anterior-posterior, as well as $10-20^{\circ}$ left oblique views were obtained. Quantitative analysis of stenosis severity was performed by an operator blinded to hemodynamic data. Minimal lumen diameter (MLD) was measured at the most tight lesion segment and compared to the reference lumen diameter (RLD) measured at the nearest normal (preferably proximal) artery segment. The percent diameter stenosis (DS) was calculated using the following formula: $\mathrm{DS}=1-(\mathrm{MLD} / \mathrm{RLD}) \times 100$ [19].

\section{Pressure measurements}

Heparin (4000-5000 U) was administered to maintain adequate anticoagulation during the procedure. Renal distal pressure (Pd) was obtained using the 0.014" Pressure Wire 5 (Radi Medical Systems, Sweden) advanced distally to the lesion, proximal pressure $(\mathrm{Pa})$ was measured from the guiding catheter tip. During pressure measurements tip was disengaged from the artery ostium to avoid pressure damping. Resting $\mathrm{Pd} / \mathrm{Pa}$ ratio was calculated as the ratio of mean distal to mean proximal pressures. Hyperemic rFFR was calculated in the same way after administration of $30 \mathrm{mg}$ of papaverine. Papaverine was diluted in non-heparinized saline and given selectively into renal artery via $3 \mathrm{~F}$ multifunctional catheter advanced distally to the lesion (if possible) and quickly removed after drug administration. Non-ionic contrast agent and nonheparinized saline were used to avoid papaverine precipitation. Mean translesional systolic pressure gradient (TSPG) was counted as the difference between proximal and distal systolic pressure. In one case, very tight stenosis was not crossable with the pressure wire and required more stiff wire and predilation - this patient was not included in the analysis.

Procedure of renal stenting was successful if angiographic residual stenosis less than $20 \%$ was obtained.

\section{Follow-up}

Before the procedure and after 6 months renal duplex Doppler and computed tomography (CT) (for potential in-stent restenosis assessment) 
were performed. Angio-CT examinations were performed with a 64-detector CT scanner (Somatom Sensation Cardiac 64; Siemens, Erlangen, Germany). For renal ultrasound, a HD11 (Philips, Eindhoven, the Netherlands) with a multiphase $2-4-\mathrm{MHz}$ convex array transducer was used. None significant restenosis ( $>50 \%$ of the vessel diameter) was detected.

Ambulatory BP measurements (ABPM) were recorded using a SpaceLabs 90207 or 90217 (Ambulatory Monitoring, Redmond, Washington, USA). Readings were obtained every 15 min during the day (6:00-22:00 h) and every $30 \mathrm{~min}$ during the night (22:00-6:00 h).

ABPM were performed before the procedure and after 6 months. One patient did not agree to have a follow-up visit. Patients were encouraged not to change their drug regimen during the follow-up period.

\section{Statistical analysis}

Continuous variables are presented as median and interquartile range. The mean deltas were assessed in Signed-Rank test and compared between subgroups using non-parametric Wilcoxon test with 2 -tailed p value below 0.05 considered significant. R-Pearson correlations coefficient were estimated for categorical variables. Statistical analysis was performed using SAS V System ver.9.2.

\section{Results}

Characteristics of the studied group are depicted in Table 1.

Median $\mathrm{Pd} / \mathrm{Pa}$ ratio was $0.84(0.79-0.91)$ and strongly correlated with TSPG $(r=-0.89, \mathrm{p}<0.001)$, MLD $(r=0.53, p<0.005)$ and DS $(r=-0.51$, $\mathrm{p}<0.005)$. No correlation was found between $\mathrm{Pd} /$ $/ \mathrm{Pa}$ ratio and GFR. After papaverine administration, proximal systolic pressure was reduced from 169 (158-187) to 153(145-169) $\mathrm{mm} \mathrm{Hg}$, distal systolic pressure from $124(110-147)$ to $103(85-116) \mathrm{mm} \mathrm{Hg}$, resulting in the increase of TSPG from 35 (23$-52) \mathrm{mm} \mathrm{Hg}$ to 53 (46-65) $\mathrm{mm} \mathrm{Hg}$ in maximal hyperemia.

The median rFFR was $0.78(0.72-0.82)$ and was not associated with GFR. Similarly, significant correlation between $\mathrm{rFFR}$ and TSPG $(r=-0.86, p<0.0001)$, as well as with MLD $(r=0.50, p<0.005)$ and DS $(r=-0.51$, $\mathrm{p}<0.005)$ was observed.

Median 15 (12-18) $\mathrm{mm}$ of stent length under pressure of 12 (10-14) atmospheres was implanted. The stent length moderately correlated both with
Table 1. Characteristics of the studied group. Data presented as median with interquartile range.

\begin{tabular}{|c|c|}
\hline Age [years] & $63.0(53-72)$ \\
\hline Males & $48.6 \%$ \\
\hline Diabetes mellitus & $22.7 \%$ \\
\hline Smoking: present/former & $5.7 \% / 48.6 \%$ \\
\hline Hypercholesterolemia & $82.9 \%$ \\
\hline GFR $[\mathrm{mL} / \mathrm{min}]$ & $69.1(61.1-85.1)$ \\
\hline Diameter stenosis [\%] & $73(66-80)$ \\
\hline $\begin{array}{l}\text { Minimal lumen diameter } \\
{[\mathrm{mm}]}\end{array}$ & $1.5(1.3-2.1)$ \\
\hline Lesion length [mm] & $12.5(9.8-13.9)$ \\
\hline TSPG at rest [mm Hg] & $35(23-52)$ \\
\hline $\begin{array}{l}\text { TSPG at max. hyperemia } \\
{[\mathrm{mm} \mathrm{Hg]}}\end{array}$ & $53(46-65)$ \\
\hline \multicolumn{2}{|l|}{$\begin{array}{l}24 \text { h ABPM systolic/diastolic } \\
\text { blood pressure: }\end{array}$} \\
\hline Before procedure & $\begin{array}{l}136(126-147) / \\
/ 71(62-79)\end{array}$ \\
\hline After 6 months & $\begin{array}{l}135(120-145) / \\
/ 69(61-77)\end{array}$ \\
\hline \multicolumn{2}{|c|}{$\begin{array}{l}\text { Antihypertension treatment } \\
\text { before procedure/after } 6 \text { months }\end{array}$} \\
\hline Number of drugs & $3.5(3-5) / 3.4(3-5)$ \\
\hline $\begin{array}{l}\text { Number of daily } \\
\text { defined doses }\end{array}$ & $\begin{array}{l}4.3(2.6-6.9) / \\
/ 4.1(2.2-6.3)\end{array}$ \\
\hline \multicolumn{2}{|l|}{$\begin{array}{l}\text { Drug class taken at } \\
\text { the study entry: }\end{array}$} \\
\hline ACEI/ARB & $82 \%$ \\
\hline Beta-blocker & $89 \%$ \\
\hline Calcium channel blocker & $73 \%$ \\
\hline Diuretic & $66 \%$ \\
\hline Alpha-1 adrenergic blocker & $25 \%$ \\
\hline Other & $11 \%$ \\
\hline
\end{tabular}

GFR - glomerular filtration rate; TSPG — translesional systolic pressure gradient ABPM — ambulatory blood pressure; measurements $\mathrm{ACEI}$ - angiotensin converting enzyme inhibitor; ARB - angiotensin II receptor blocker

$\mathrm{Pd} / \mathrm{Pa}(\mathrm{r}=-0.46, \mathrm{p}<0.01)$, and $\mathrm{rFFR}(\mathrm{r}=-0.47$, $\mathrm{p}<0.01)$. Angiographic procedural success was obtained in all patients. Median $\mathrm{Pd} / \mathrm{Pa}$ ratio and rFFR after stent implantation were: $0.98(0.95-1)$ and $0.98(0.94-1)$, respectively. Before entering the study, patients were treated with 4.3 (2.6-6.9) defined daily doses of 3.5 (3-5) antihypertensive drugs.

Neither $\mathrm{Pd} / \mathrm{Pa}$ ratio nor $\mathrm{rFFR}$ predicted hypertension response after renal stenting - the results of the ABPM are presented in Table 2. Only mild difference in daytime BP was observed between patients with $\mathrm{Pd} / \mathrm{Pa}$ ratio below and above 0.9 . However, it resulted from increased BP in patients with $\mathrm{Pd} / \mathrm{Pa}$ ratio $>0.9$, probably due to the changes 
Table 2. Results of ambulatory blood pressure (BP) measurements in relation to baseline hemodynamic parameters. Data presented as median with interquartile range.

\begin{tabular}{|c|c|c|c|c|c|c|}
\hline & $\mathrm{Pd} / \mathrm{Pa}<0.9$ & $\mathrm{Pd} / \mathrm{Pa} \geq 0.9$ & $\mathbf{P}$ & rFFR $<0.8$ & rFFR $\geq 0.8$ & $\mathbf{P}$ \\
\hline \multicolumn{7}{|l|}{ Systolic BP } \\
\hline Before intervention & 137 (125-148) & 135 (120-142) & NS & 136 (122-149) & 137.5 (129-144) & NS \\
\hline After 6 months & 135 (120-144) & $136(125-147)$ & NS & $137(120-146)$ & 131 (119-143) & NS \\
\hline $\mathrm{p}^{*}$ & NS & NS & & NS & NS & \\
\hline \multicolumn{7}{|l|}{ Change: } \\
\hline 24 hours & $-4(-14-2.5)$ & $0(-4-15)$ & NS & $-2(-6-13)$ & $-2(-7-5.5)$ & NS \\
\hline Daytime & $-4(-14-13.5)$ & $9.5(2-17)$ & $<0.05$ & $3(-11-17)$ & $4(-4-10)$ & NS \\
\hline Night-time & $-1(-14-5)$ & $-2(-8-9)$ & NS & $1(-14-8)$ & $-2(-8-6)$ & NS \\
\hline \multicolumn{7}{|l|}{ Diastolic BP } \\
\hline Before intervention & 71 (62-79) & 72 (59-79) & NS & 72 (63-79) & $70(58-77)$ & NS \\
\hline After 6 months & $68(59-77)$ & $74(63-77)$ & NS & 70 (61-85) & $68(61-75)$ & NS \\
\hline$p^{*}$ & NS & NS & & NS & NS & \\
\hline \multicolumn{7}{|l|}{ Change: } \\
\hline 24 hours & $-3(-6.5-2.5)$ & $2(-2-5)$ & NS & $-1(-5-3)$ & $-0.5(-7.5-5)$ & NS \\
\hline Daytime & $-2.5(-7.5-2.0)$ & $3(-2.5-10)$ & $<0.05$ & $1(-4-6)$ & $1(-6-3)$ & NS \\
\hline Night-time & $-3(-7-3)$ & $2(-10-8)$ & NS & $-3(-7-4)$ & $1(-5-3)$ & NS \\
\hline
\end{tabular}

* $p$ for difference in blood pressure between baseline and 6 months follow-up; $\mathrm{Pd} / \mathrm{Pa}$ - renal artery pressures ratio (distal/proximal); rFFR - renal fractional flow reserve

in antihypertensive treatment during the follow-up period $(-0.9$ vs. 0.1 drug, $\mathrm{p}<0.05)$.

\section{Discussion}

In our study, the relationship between hemodynamic parameters and $\mathrm{BP}$ response after renal artery stenting was not confirmed. Neither resting $\mathrm{Pd} / \mathrm{Pa}$ ratio nor $\mathrm{rFFR}$ were related to $\mathrm{ABPM}$ changes after renal revascularization.

The utility of $\mathrm{Pd} / \mathrm{Pa}$ ratio and $\mathrm{rFFR}$ as diagnostic tools in RAS assessment was demonstrated in only several trials [13-16]. Thus, the evaluation of its potential prognostic value in hypertension response after renal revascularization was urgently required. Previously published studies with rFFR or hyperemic systolic translesional gradient used only office BP measurements as the study endpoint $[20,21]$. Since they have obvious limitations, trials with 24-h ABPM were expected. Our study is one of the first studies using ABPM in renal stenting evaluation in relation to hemodynamic measurements. First study using ABPM was published in December 2010 [22]. In this paper, in contrast to our results, the association between pressure gradients and $\mathrm{BP}$ improvement after renal stenting was observed. It is of note, that there are a few important differences between this study and reported by Mangiacapra et al. [22]. First of all, we used only papaverine bolus as hyperemic stimulus. $30 \mathrm{mg}$ of papaverine as adequate dose in achieving of maximal hyperemia was previously proved [13]. Mangiacapra et al. [22] used not only papaverine but also dopamine in hyperemia inducement. And dopamine-induced, in contrast to papaverine-induced, mean gradient predicted hypertension response. Secondly, we calculated the baseline and hyperemic pressures ratios (called $\mathrm{Pd} / \mathrm{Pa}$ and $\mathrm{rFFR}$, respectively). In the study by Mangiacapra et al. [22] only mean hyperemic gradient (not ratio) was related to BP improvement. Thirdly, we performed slightly longer follow-up (6 vs. 3 months). And finally, our group had generally better pharmacologically controlled hypertension - mean systolic pressure obtained from ABPM was significantly lower than in the compared trial. That is probably the main reason why the overall benefit from revascularization was rather modest. The results are similar to ASTRAL study - the ever largest trial comparing medical therapy and revascularization - where renal stenting did not provide any additional benefit to standard medical therapy [11]. The ASTRAL study raised some doubts and criticism regarding the trial design — published elsewhere [23].

\section{Limitations of the study}

There are a few limitations to our study. Our group was relatively small - but one should take into account that recruitment to renal stenting 
trials is very challenging. In ASTRAL study, the recruitment phase lasted 7 years and approximately 2 patients per year in each site were enrolled. After ASTRAL results presentation, number of revascularization procedures in patients with RAS significantly decreased. Our results represent the experience of 1 center, with 35 patients recruited. For comparison, previously published trials included from 13 to 61 patients. Thus, the results should be interpreted with caution.

Our group was quite heterogeneous with wide range of pre-procedure ABPM, that resulted from recruiting all consecutive patients referred to renal angioplasty. It might have had an influence on different $\mathrm{BP}$ response after revascularization and limited the value of obtained results.

\section{Conclusions}

Our study has found that physiological assessment of RAS based on papaverine-induced hyperemia does not predict BP response after renal artery stenting. Despite other trials, staying in contrast to our results, evaluating dopamine induced gradients and papaverine induced ratios, large multicenter trials with uniform methodology are still needed.

\section{Acknowledgements}

This research was supported by grant $2 \mathrm{P} 05 \mathrm{~B} 0$

2530 from Ministry of Science and Higher Education. ClinicalTrials.gov identifier: NCT01128933.

Conflict of interest: none declared

\section{References}

1. Caps MT, Perissinotto C, Zierler RE et al. Prospective study of atherosclerotic disease progression in renal artery. Circulation, 1998; 98: 2866-2872.

2. Crowley JJ, Santos RM, Peter RH et al. Progression of renal artery stenosis in patients undergoing cardiac catheterization. Am Heart J, 1998; 136: 913-918.

3. Zierler RE, Bergelin RO, Davidson RC, Cantwell-Gab K, Pollisar NL, Strandness DE. A prospective study of disease progression in patients with atherosclerotic renal artery disease. Am J Hypertens, 1996; 9: 1055-1061.

4. Conlon PJ, Athirakul K, Kovalik E et al. Survival in renal vascular disease. J Am Soc Nephrol, 1998; 9: 252-256.

5. Conlon PJ, Little MA, Pieper K, Mark DB. Severity of renal vascular disease predicts mortality in patients undergoing coronary angiography. Kidney Int, 2001; 60: 1490-1497.

6. van de Ven PJ, Kaatee R, Beutler JJ et al. Arterial stenting and balloon angioplasty in ostial atherosclerotic renovascular disease: A randomised trial. Lancet, 1999; 353: 282-286.

7. Webster J, Marshall F, Abdalla M et al. Randomised comparison of percutaneous angioplasty vs. continued medical therapy for hypertensive patients with atheromatous renal artery stenosis. Scottish and Newcastle Renal Artery Stenosis Collaborative Group. J Hum Hypertens, 1998; 12: 329-335.

8. Plouin PF, Chatellier G, Darne B, Raynaud A. Blood pressure outcome of angioplasty in atherosclerotic renal artery stenosis: A randomized trial. Essai Multicentrique Medicaments vs Angioplastie (EMMA) Study Group. Hypertension, 1998; 31: 823-829.

9. Leertouwer TC, Gussenhoven EJ, Bosch JL et al. Stent placement for renal arterial stenosis: Where do we stand? A meta-analysis. Radiology, 2000; 216: 78-85.

10. van Jaarsveld BC, Krijnen P, Pieterman H et al. The effect of balloon angioplasty on hypertension in atherosclerotic renal-artery stenosis. Dutch Renal Artery Stenosis Intervention Cooperative Study Group. N Engl J Med, 2000; 342: 1007-1014.

11. Wheatley K, Ives N, Gray R et al.; ASTRAL Investigators. Revascularization versus medical therapy for renal-artery stenosis. N Engl J Med, 2009; 361: 1953-1962.

12. Bax L, Woittiez AJ, Kouwenberg HJ et al. Stent placement in patients with atherosclerotic renal artery stenosis and impaired renal function: A randomized trial. Ann Intern Med, 2009; 150: 840-848, W150-W151.

13. Subramanian R, White CJ, Rosenfield K et al. Renal fractional flow reserve: A hemodynamic evaluation of moderate renal artery stenoses. Catheter Cardiovasc Interv, 2005; 64: 480-486.

14. De Bruyne B, Manoharan G, Pijls NH et al. Assessment of renal artery stenosis severity by pressure gradient measurements. J Am Coll Cardiol, 2006; 48: 1851-1855.

15. Drieghe B, Madaric J, Sarno G et al. Assessment of renal artery stenosis:side-by-side comparison of angiography and duplex ultrasound with pressure gradient measurements. Eur Heart J, 2008; 29: 517-524.

16. Jones NJ, Bates ER, Chetcuti SJ, Lederman RJ, Grossman PM. Usefulness of translesional pressure gradient and pharmacological provocation for the assessment of intermediate renal artery disease. Catheter Cardiovasc Interv, 2006; 68: 429-434.

17. 1999 World Health Organization International Society of Hypertension Guidelines for the Management of Hypertension. Guidelines Subcommittee. J Hypertens, 1999; 17: 151-183.

18. Levey AS, Bosch JP, Lewis JB, Greene T, Rogers N, Roth D. A more accurate method to estimate glomerular filtration rate from serum creatinine: A new prediction equation. Modification of Diet in Renal Disease Study Group. Ann Intern Med, 1999; 130: 461-470.

19. Uchata A, Matsuguchi T, Bittl JA et al. Accuracy of electronic digital calipers compared with quantitative angiography in measuring coronary arterial diameter. Circulation, 1993; 88: 1724-1729.

20. Mitchell JA, Subramanian R, White CJ et al. Predicting blood pressure improvement in hypertensive patients after renal artery stent placement: Renal fractional flow reserve. Catheter Cardiovasc Interv, 2007; 69: 685-689.

21. Leesar MA, Varma J, Shapira A et al. Prediction of hypertension improvement after stenting of renal artery stenosis: comparative accuracy of translesional pressure gradients, intravascular ultrasound, and angiography. J Am Coll Cardiol, 2009; 53: 2363-2371.

22. Mangiacapra F, Trana C, Sarno G et al. Translesional pressure gradients to predict blood pressure response after renal artery stenting in patients with renovascular hypertension. Circ Cardiovasc Interv, 2010; 3: 537-542.

23. White CJ. Kiss my astral: One seriously flawed study of renal stenting after another. Catheter Cardiovasc Interv, 2010; 75: 305-307. 